\title{
Fractalkine as an Important Target of Aspirin in the Prevention of Atherogenesis
}

\author{
Editorial to: "Aspirin Inhibits Fractalkine Expression in Atherosclerotic Plaques \\ and Reduces Atherosclerosis in ApoE Gene Knockout Mice" by H. Liu et al.
}

\author{
Heidi Noels • Christian Weber
}

Published online: 23 December 2009

(C) Springer Science+Business Media, LLC 2009

Since its discovery in the 1850 s, aspirin, or acetylsalicylic acid, has been widely used as an anti-inflammatory, analgesic and antipyretic drug. In addition, aspirin therapy reduces the incidence of myocardial infarction in patients with a high risk on occlusive vascular events [1], which has been attributed to aspirin's anti-platelet properties. By inhibiting COX activity, low-dose aspirin mainly prevents prothrombotic thromboxane $\mathrm{A}_{2}$ production in platelets due to their inability to regenerate COX1. This shifts the haemostatic thromboxane-prostacyclin balance and favours the prostacyclin-mediated inhibition of platelet aggregation, thereby reducing the risk of thrombus formation in highrisk patients [2]. Interestingly, aspirin administration has also been reported to reduce the development and progression of atherosclerosis in hyperlipidaemic mice [3-6]. This property goes beyond aspirin's ability to block COX1 activity, as COX1 inhibition can only reduce atherosclerotic plaque formation in early stages, without affecting the progression of established lesions [7]. This emphasizes the importance of COX-independent anti-inflammatory actions of aspirin in its therapeutic value.

Atherosclerosis development and progression are indeed closely linked to inflammatory processes in the vessel wall [8]. The denudation and activation of the arterial endothelial cell (EC) layer by shear stress, reactive oxygen species (ROS) and oxidized low density lipoproteins (oxLDL) results in the production of soluble chemokines that recruit

H. Noels $\cdot$ C. Weber $(\square)$

Institute for Molecular Cardiovascular Research (IMCAR),

RWTH Aachen University,

Aachen, Germany

e-mail: cweber@ukaachen.de leukocytes to the site of inflammation. Initial selectinmediated rolling of monocytes over the vessel wall is followed by their firm adhesion and transmigration into the vessel, where they transform into macrophages involved in the uptake of accumulated modified lipids. Crucial for this firm monocyte-EC adhesion are the integrins on the monocyte cell surface that interact with their corresponding ligands on ECs. Also EC-mobilized chemokines play an important role in this adhesion step, as they increase the integrin avidity by stimulating their respective G-protein coupled chemokine receptors on monocytes. Recently, it was shown that inflammatory Ly-6 $\mathrm{C}^{\text {high }}$ monocytes require the chemokine receptors CCR2, CCR5 and CX3CR1 to enter into atherosclerotic lesions, while the migration of Ly${ }_{6} \mathrm{C}^{\text {low }}$ monocytes did not rely on CX3CR1, but was partially dependent on CCR5 [9]. The importance of these chemokine receptors and their chemokine ligands in atherosclerosis is further demonstrated by their respective knock-out or antagonist treatment in hyperlipidaemic mice, displaying a reduction in atherosclerotic plaque formation and lesional macrophage accumulation, e.g. when targeting RANTES(CCL5)/CCR5 [10, 11], platelet-derived CCL5/ CXCL4 heteromers [12], MCP1(CCL2)/CCR2 [11] and fractalkine (CX3CL1)/CX3CR1 [13-15]. These findings underline the important contribution of chemokinemediated monocyte/macrophage accumulation to atherosclerotic lesion formation and open a new direction of therapeutic drug design and application.

Interestingly, aspirin has been shown to affect different steps in the inflammatory events associated with atherogenesis. As such, aspirin protects ECs from oxidative stress by interfering with the production of ROS and by reducing the ROS- and oxLDL-induced dysfunction of ECs [16]. In 
addition, aspirin reduces leukocyte chemotaxis and adhesion on ECs $[17,18]$, which can explain the lower foam cell content in atherosclerotic plaques of hypercholesterolaemic mice treated with aspirin $[4,6]$.This reduction of leukocyte recruitment and adhesion can (at least partly) be ascribed to the ability of aspirin to inhibit the activity of IKK $\beta$ [19] and the proteasome [20], which together underlie the aspirininduced defect in the phosphorylation and degradation of I $\mathrm{B}-\alpha$, the inhibitor protein of NF- $\mathrm{kB}[21,22]$. In this way, aspirin interferes with NF- $\mathrm{KB}$ activation [21] and blocks the expression of NF- $\mathrm{KB}$ target genes involved in monocyte chemotaxis, as CCL2 [23], and monocyte-EC adhesion, as E-selectin, VCAM1 and ICAM1 [18, 22].

In this issue, Liu and colleagues [24] observed that the reduction in atherosclerotic plaque size in hyperlipidaemic mice upon aspirin administration was associated with a reduced lesional expression of fractalkine, another NF- $\mathrm{kB}$ target gene important in atherosclerosis [13]. Although the macrophage accumulation in the lesions was not measured in this study, previous data link reduced fractalkine expression to a lower foam cell content in the plaques [13]. In this context; fractalkine is unique in that it can both function as a soluble chemoattractant and as a membranebound leukocyte adhesion molecule, independent of selectins or integrins. Whereas this intrinsic adhesion function mediates initial, weak leukocyte interactions, the binding of fractalkine to its chemokine receptor CX3CR1 increases leukocytic integrin avidity, inducing firm leukocyte adhesion [25]. This unique adhesive function of fractalkine might explain why CX3CR1-expressing cells bound more rapidly and stronger to immobilized fractalkine than to VCAM1 [26]. Interestingly, it was shown that fractalkine and CCR2 contribute independently to monocyte/macrophage recruitment into atherosclerotic lesions [27]. Although fractalkine deletion had a considerable lower atheroprotective effect compared to the deletion of CCR2, fractalkine deficiency further reduced macrophage accumulation and atherosclerotic lesion formation in $\mathrm{CCR} 2^{-/-}$mice [27]. This interesting finding underlines the synergistic effect of chemokines and chemokine receptors in monocyte recruitment during atherogenesis, and indicates that a simultaneous blocking of two or more chemokine receptors might be beneficial in the treatment of atherosclerosis [27].

And this is precisely what underlies the property of aspirin to efficiently reduce leukocyte chemotaxis and adhesion on ECs: by interfering with NF- $\mathrm{KB}$ activation, aspirin reduces the expression of synergistically acting chemokines as CCL2 and fractalkine, and in addition downregulates monocyte adhesion molecules, as VCAM1 and - again - fractalkine. This property can be linked to the ability of aspirin to attenuate atherosclerosis in mice [3-6], although it should be mentioned that this beneficial outcome was not observed by all groups studying the effects of aspirin administration on atherogenesis [28, 29]. These discrepancies could be due to different animal models used, to differences in the high-fat diet and aspirin administration, and to the different time points at which atherosclerosis was examined. Furthermore, it remains unclear in how far aspirin and fractalkine exert true protective, anti-atherosclerotic functions in humans. Although CX3CR1 gene polymorphisms have been associated with a reduced risk of coronary artery disease (CAD) and therapeutics interfering with fractalkine activity might thus be beneficial in the treatment of CAD [30], the effectiveness of routine aspirin therapy for the primary prevention of $\mathrm{CAD}$ in healthy individuals remains high uncertain and requires further research [31].

\section{References}

1. Collaborative meta-analysis of randomised trials of antiplatelet therapy for prevention of death, myocardial infarction, and stroke in high risk patients. BMJ 2002;324:71-86.

2. Tohgi H, Konno S, Tamura K, Kimura B, Kawano K. Effects of low-to-high doses of aspirin on platelet aggregability and metabolites of thromboxane A2 and prostacyclin. Stroke. 1992;23:1400-3.

3. Paul A, Calleja L, Camps J, Osada J, Vilella E, Ferre N, et al. The continuous administration of aspirin attenuates atherosclerosis in apolipoprotein E-deficient mice. Life Sci. 2000;68:45765.

4. Cyrus T, Sung S, Zhao L, Funk CD, Tang S, Pratico D. Effect of low-dose aspirin on vascular inflammation, plaque stability, and atherogenesis in low-density lipoprotein receptor-deficient mice. Circulation. 2002;106:1282-7.

5. Tous M, Ferre N, Vilella E, Riu F, Camps J, Joven J. Aspirin attenuates the initiation but not the progression of atherosclerosis in apolipoprotein E-deficient mice fed a high-fat, high-cholesterol diet. Basic Clin Pharmacol Toxicol. 2004;95:15-9.

6. Cyrus T, Yao Y, Tung LX, Pratico D. Stabilization of advanced atherosclerosis in low-density lipoprotein receptor-deficient mice by aspirin. Atherosclerosis. 2006;184:8-14.

7. Belton OA, Duffy A, Toomey S, Fitzgerald DJ. Cyclooxygenase isoforms and platelet vessel wall interactions in the apolipoprotein E knockout mouse model of atherosclerosis. Circulation. 2003;108:3017-23.

8. Weber C, Zernecke A, Libby P. The multifaceted contributions of leukocyte subsets to atherosclerosis: lessons from mouse models. Nat Rev Immunol. 2008;8:802-15.

9. Tacke F, Alvarez D, Kaplan TJ, Jakubzick C, Spanbroek R, Llodra J, et al. Monocyte subsets differentially employ CCR2, $\mathrm{CCR} 5$, and $\mathrm{CX} 3 \mathrm{CR} 1$ to accumulate within atherosclerotic plaques. J Clin Invest. 2007;117:185-94.

10. Veillard NR, Kwak B, Pelli G, Mulhaupt F, James RW, Proudfoot AE, et al. Antagonism of RANTES receptors reduces atherosclerotic plaque formation in mice. Circ Res. 2004;94:253-61.

11. Zernecke A, Shagdarsuren E, Weber C. Chemokines in atherosclerosis: an update. Arterioscler Thromb Vasc Biol. 2008;28:1897-908.

12. Koenen RR, von Hundelshausen P, Nesmelova IV, Zernecke A, Liehn EA, Sarabi A, et al. Disrupting functional interactions between platelet chemokines inhibits atherosclerosis in hyperlipidemic mice. Nat Med. 2009;15:97-103. 
13. Teupser D, Pavlides S, Tan M, Gutierrez-Ramos JC, Kolbeck R, Breslow JL. Major reduction of atherosclerosis in fractalkine (CX3CL1)-deficient mice is at the brachiocephalic artery, not the aortic root. Proc Natl Acad Sci USA. 2004;101:17795-800.

14. Lesnik P, Haskell CA, Charo IF. Decreased atherosclerosis in CX3CR1-/- mice reveals a role for fractalkine in atherogenesis. J Clin Invest. 2003;111:333-40.

15. Combadiere C, Potteaux S, Gao JL, Esposito B, Casanova S, Lee EJ, et al. Decreased atherosclerotic lesion formation in CX3CR1/apolipoprotein E double knockout mice. Circulation. 2003;107:1009-16.

16. Khan Q, Mehta JL. Relevance of platelet-independent effects of aspirin to its salutary effect in atherosclerosis-related events. J Atheroscler Thromb. 2005;12:185-90.

17. Voisard R, Fischer R, Osswald M, Voglic S, Baur R, Susa M, et al. Aspirin $(5 \mathrm{mmol} / \mathrm{L})$ inhibits leukocyte attack and triggered reactive cell proliferation in a $3 \mathrm{D}$ human coronary in vitro model. Circulation. 2001;103:1688-94.

18. Weber C, Erl W, Pietsch A, Weber PC. Aspirin inhibits nuclear factor-kappa B mobilization and monocyte adhesion in stimulated human endothelial cells. Circulation. 1995;91:1914-7.

19. Yin MJ, Yamamoto Y, Gaynor RB. The anti-inflammatory agents aspirin and salicylate inhibit the activity of I(kappa)B kinase-beta. Nature. 1998;396:77-80.

20. Dikshit P, Chatterjee M, Goswami A, Mishra A, Jana NR. Aspirin induces apoptosis through the inhibition of proteasome function. J Biol Chem. 2006;281:29228-35.

21. Kopp E, Ghosh S. Inhibition of NF-kappa B by sodium salicylate and aspirin. Science. 1994;265:956-9.

22. Pierce JW, Read MA, Ding H, Luscinskas FW, Collins $T$. Salicylates inhibit I kappa B-alpha phosphorylation, endothelialleukocyte adhesion molecule expression, and neutrophil transmigration. J Immunol. 1996;156:3961-9.

23. Dragomir E, Tircol M, Manduteanu I, Voinea M, Simionescu M. Aspirin and PPAR-alpha activators inhibit monocyte chemoattractant protein-1 expression induced by high glucose concentration in human endothelial cells. Vascul Pharmacol. 2006;44:440-9.

24. Liu H, Jiang D, Zhang S, Ou B. Aspirin inhibits fractalkine expression in atherosclerotic plaques and reduces atherosclerosis in ApoE gene knockout mice. Cardiovasc Drugs Ther 2010;24: this issue

25. Umehara H, Bloom ET, Okazaki T, Nagano Y, Yoshie O, Imai T. Fractalkine in vascular biology: from basic research to clinical disease. Arterioscler Thromb Vasc Biol. 2004;24:34-40.

26. Haskell CA, Cleary MD, Charo IF. Molecular uncoupling of fractalkine-mediated cell adhesion and signal transduction. Rapid flow arrest of CX3CR1-expressing cells is independent of Gprotein activation. J Biol Chem. 1999;274:10053-8.

27. Saederup N, Chan L, Lira SA, Charo IF. Fractalkine deficiency markedly reduces macrophage accumulation and atherosclerotic lesion formation in CCR2-/- mice: evidence for independent chemokine functions in atherogenesis. Circulation. 2008;117:1642-8.

28. Schulz C, Konrad I, Sauer S, Orschiedt L, Koellnberger M, Lorenz R, et al. Effect of chronic treatment with acetylsalicylic acid and clopidogrel on atheroprogression and atherothrombosis in ApoE-deficient mice in vivo. Thromb Haemost. 2008;99:190-5.

29. Cayatte AJ, Du Y, Oliver-Krasinski J, Lavielle G, Verbeuren TJ, Cohen RA. The thromboxane receptor antagonist S18886 but not aspirin inhibits atherogenesis in apo E-deficient mice: evidence that eicosanoids other than thromboxane contribute to atherosclerosis. Arterioscler Thromb Vasc Biol. 2000;20:1724-8.

30. McDermott DH, Halcox JP, Schenke WH, Waclawiw MA, Merrell MN, Epstein N, et al. Association between polymorphism in the chemokine receptor CX3CR1 and coronary vascular endothelial dysfunction and atherosclerosis. Circ Res. 2001;89:401-7.

31. Baigent C, Blackwell L, Collins R, Emberson J, Godwin J, Peto $\mathrm{R}$, et al. Aspirin in the primary and secondary prevention of vascular disease: collaborative meta-analysis of individual participant data from randomised trials. Lancet. 2009;373:1849-6. 